\title{
PATRIMONIO Y PLAN URBANO EN LIMA: APUESTAS Y DESAFÍOS DEL DIAGNÓSTICO Y PROPUESTA DE PATRIMONIO EDIFICADO EN EL PLAM 2035 ${ }^{(*)}$
}

\author{
HERITAGE AND URBAN PLANNING IN LIMA: BET AND CHALLENGES OF THE DIAGNOSIS AND \\ PROPOSAL OF BUILT HERITAGE INTO THE PLAM 2035
}

ROSARIO ARIZA FRITAS ${ }^{(\star *)} Y_{\text {JOSÉ CARLOS HAYAKAWA CASAS }}^{[\star \star *]}$

Fecha de recepción: 26 de abril de 2015

Fecha de aprobación: 01 de junio de 2015

\section{RESUMEN}

El patrimonio edificado constituye un espectro esencial y dinámico de la actividad humana. Representa un privilegio y desafío tanto cuantitativa como cualitativamente, y su adecuada gestión puede devenir en el incremento de la calidad de vida de las comunidades de Lima. El realizar un análisis y propuesta de gestión del patrimonio edificado en Lima contribuye a desarrollar una panorámica, y a sistematizar las "lecciones aprendidas". Este texto profundiza en la valiosa y singular experiencia de construcción del diagnóstico/propuesta del patrimonio edificado como componente sectorial y horizonte transversal en el marco del Plan Metropolitano de Desarrollo Urbano de Lima (PLAM 2035). Reconocer el proceso de elaboración de esta documentación permitirá determinar el valor de sus principales apuestas y estrategias para lidiar con las carencias y problemas que se suscitaron en un entorno con una débil institucionalidad y ciudadanía cultural, pero también con oportunidades desde el liderazgo de la Administración Pública, específicamente el Gobierno de la ciudad, para concertar esfuerzos y avances.

\section{PALABRAS CLAVE}

Patrimonio edificado, Lima, planificación urbana

\section{ABSTRACT}

Built heritage is an essential and dynamic dimension of human activity. It encompasses privileges and challenges, qualitatively and quantitatively. The adequate management of this cultural heritage can mean an increase in quality of life for the communities of Lima. The analysis and proposal of built heritage management's in Lima helps to develop a panoramical view and to organize pertinent data in a systematic way, much like "learned lessons". This text explores the valuable and unique experience of developing the diagnosis and proposal of built heritage as a sectorial component and cross-horizon in the context of the Metropolitan Urban Development Plan of Lima (PLAM 2035). Recognizing the process of elaboration of this documentation will allow the assessment of its main force ideas and strategies to deal with the deficits and problems given rise by an environment with weak institutions and cultural citizenship, but also opportunities from the leadership of the Public Administration, specifically the City Government, to coordinate efforts and progress.

\section{KEYWORDS}

Built heritage, Lima, urban planning

(*) El presente estudio desarrolla los problemas y desafíos que conllevó el proceso de elaboración del Diagnóstico y la Propuesta de Patrimonio Edificado en el marco del Plan Metropolitano de Desarrollo Urbano de Lima al 2035 (PLAM 2035) de la Municipalidad Metropolitana de Lima, desarrollado entre 2013 y 2014, del cual los autores participaron de forma activa, como miembro del equipo de Análisis Territorial y como especialista encargado respectivamente. $\left.{ }^{(* *}\right)$ Arquitecta graduada de la Universidad Nacional de Ingeniería. Ha trabajado en proyectos de arquitectura y planificación urbana. Formó parte del equipo del Plan Metropolitano de Desarrollo Urbano de Lima y el Callao al 2035 (PLAM 2035). Realizó la Diplomatura en Habitabilidad Básica para la Inclusión Social, organizada por la Universidad Nacional de Ingeniería y la Universidad Politécnica de Madrid. Contacto: charitoariza@gmail.com

$\left.{ }^{(* * *}\right)$ Arquitecto, magíster en Arquitectura con mención en Renovación Urbana (Universidad Nacional de Ingeniería, UNI). Investigador y docente de la UNI en pregrado y en las maestrías en Regeneración Urbana y Conservación del Patrimonio Edificado, en la maestría en Gestión del Patrimonio Cultural de la Universidad Nacional Mayor de San Marcos y en la maestría en Gestión Cultural, Patrimonio y Turismo de la Universidad San Martín de Porres. Es miembro de la Junta Directiva del Comité Nacional de ICOMOS y del Grupo de Estudios de la Inmigración Japonesa al Perú s. XVII-XX del Instituto Riva Agüero de la Pontificia Universidad Católica del Perú. Trabajó como especialista en Regeneración Urbana y Patrimonio en la elaboración del Plan Metropolitano de Desarrollo Urbano de Lima al 2035 y actualmente se desempeña como Director del Instituto de Conservación del Patrimonio Víctor Pimentel Gurmendi, de la Facultad de Arquitectura de la UNI. Contacto: josehayakawa@gmail.com. 


\section{El Patrimonio Edificado en el marco del PLAM 2035}

El abordaje de la temática de patrimonio edificado en el Plan Metropolitano de Desarrollo Urbano de Lima al 2035 exigió una serie de "reflexiones" que fueron orientándolo durante un proceso de retroalimentación permanente. ¿Qué es el patrimonio edificado en el contexto del patrimonio cultural de la Lima contemporánea? ¿Qué debe considerarse como tal? ¿Cuánto patrimonio edificado tiene Lima Metropolitana? ¿Dónde está emplazado? ¿Por qué conservarlo, en el marco de la dinámica urbana contemporánea? ¿Cómo ponerlo en valor social?

El intento de responder a estas preguntas y la reconstrucción de los antecedentes permitirán valorar el esfuerzo que implicó emprender, por primera vez, la incorporación un capítulo sobre patrimonio edificado (fuera del Centro Histórico) en los planes de desarrollo urbano desarrollados para Lima Metropolitana.

\section{Lo Edificado como Patrimonio en Lima}

Lima es la ciudad capital y región más importante del Perú, y una de las más importantes de América, por su gran legado patrimonial en cuanto a extensión y densidad monumental. Este conjunto monumental (arquitectónico y urbano) expresa la magnitud y calidad de la respuesta antrópica e histórica del pueblo de Lima para responder y transformar sus singulares circunstancias climáticas (clima subtropical y humedad sempiterna), geográficas (latitud Sur, y presencia de un paisaje desértico entre la cordillera de Llos Andes y un mar bañado por la corriente de Humboldt) y sísmicas (ubicación central en el Círculo de Fuego del Pacífico, donde ocurre el $80 \%$ de la actividad sísmica mundial) generando alta cultura.

El patrimonio cultural inmueble en Lima Metropolitana y El Callao se divide operativamente en dos grupos: el patrimonio arqueológico prehispánico (incluye los monumentos declarados, así como aquellos que aparecen en inventarios pero no cuentan con declaración oficial) y el patrimonio histórico colonial y republicano (abarca la lista oficial del Ministerio de Cultura: todos los monumentos declarados de dichos períodos). Ambos grupos comprenden más de 2000 unidades.

El patrimonio arqueológico prehispánico (anterior a la llegada de los españoles en el s. XVI) está conformado por 538 monumentos arqueológicos. De estos, 495 están en Lima y 43 se encuentran en El Callao (19 de ellos en la Isla San Lorenzo). El patrimonio arqueológico prehispánico se subdivide en cinco tipos: conjunto edificado, edilicia especial, fragmentos de construcciones, sitio natural y otros. Por lo tanto, existe una amplia variedad de monumentos, desde la zona arqueológica monumental de Pachacamac, de 465.31 hectáreas, correspondiente a la categoría edilicia especial, hasta el sitio arqueológico Túpac Amaru B, de 0.06 hectáreas, en la categoría de fragmentos de construcciones (montículo). (Figura 1)

El patrimonio histórico colonial y republicano (posterior a la llegada de los españoles en el s. XVI) incluye 1650 monumentos declarados, que representan el $32.58 \%$ del total nacional. Los monumentos coloniales y republicanos son muy diversos según sus tipos específicos; pueden ser desde una vivienda unifamiliar colonial hasta conjuntos excepcionales como las zonas monumentales del Rímac y el Centro de Lima, que conforman el Centro Histórico. Gran parte de este ha sido incluido en la "Lista del Patrimonio Cultural de la Humanidad" elaborado por Unesco en 1991.

La ubicación del patrimonio cultural inmueble en Lima Metropolitana determina, en gran medida, su pervivencia y estado de conservación. Casi todos los 50 distritos que conforman Lima Metropolitana (provincias de Lima y Callao) contienen bienes con algún grado de protección legal. En los distritos periurbanos de Lima Norte, Lima Este y Lima Sur (San Juan de Lurigancho, Lurigancho-Chosica, Cieneguilla, Pachacamac, Ate y 

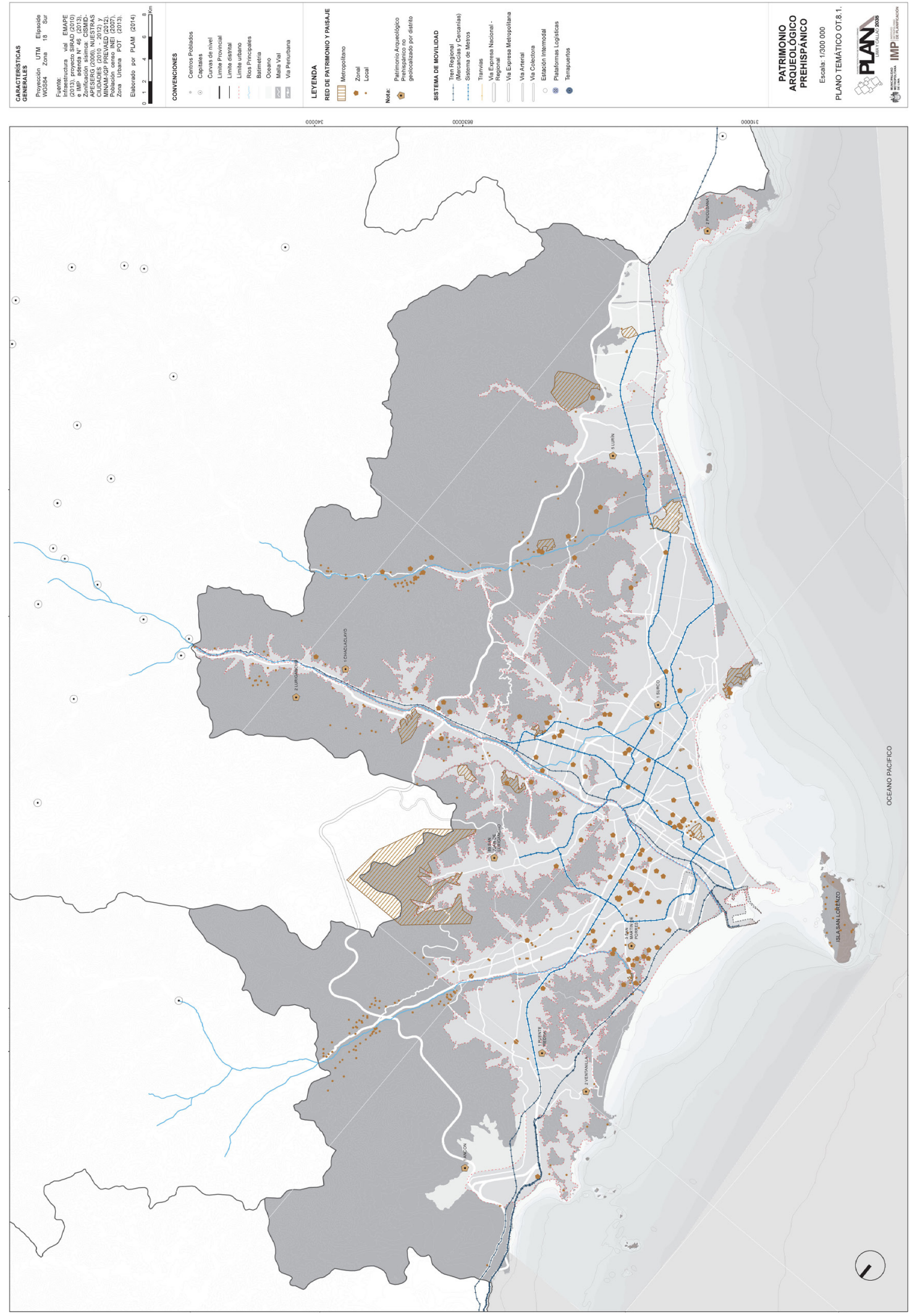

Figura 1. Patrimonio arqueológico prehispánico en Lima Metropolitana.

Fuente: Municipalidad Metropolitana de Lima, 2015. 
Carabayllo entre los distritos con mayor cantidad y densidad monumental) existe una importante concentración de patrimonio arqueológico prehispánico, más del $60 \%$ del total inventariado hasta la fecha. Lamentablemente, en esos sectores los Gobiernos locales no pueden afrontar completamente y por sí mismos planes, programas y proyectos de puesta en valor social de dichos bienes monumentales; así, consecuencia de tal gestión deficitaria es su situación de abandono y deterioro. En cambio, la mayor parte de los monumentos arqueológicos prehispánicos sobre los que se cuenta con más información y registro se encuentran en Lima Centro. Sin embargo, a su vez, es el área que haexperimentado mayor pérdida patrimonial. Más del $85 \%$ del patrimonio histórico colonial y republicano se encuentra en Lima Centro y El Callao, donde la ocupación urbana colonial se concentró y consolidó a lo largo del tiempo (Lima Cercado, Rímac, Barranco y Pueblo Libre entre los distritos con mayor cantidad y densidad monumental).

Lamentablemente, la situación de nuestro patrimonio monumental sigue siendo un problema francamente desatendido, tanto de parte de los órganos competentes como por la sociedad civil en su conjunto. Es una cruda realidad el hecho de que la comprobación del acelerado proceso de agresión y anulación de nuestro patrimonio monumental no tenga el impacto social correspondiente. Esta situación fue ya retratada en el pasado por el Arq. Santiago Agurto Calvo (1992), quien en un análisis plenamente vigente manifiesta como factores condicionantes de este fenómeno los siguientes:

- La equivocada concepción y mala estructuración del Estado peruano.

- La inexistencia de una vigorosa conciencia de identidad y solidaridad nacionales.

- La mentalidad etnocentrista, aristocratizante y alienada de nuestras clases gobernantes y pudientes.

- La ignorancia y pobreza de nuestras mayorías.

- La carencia y precariedad de la infraestructura estatal. (p. 6)

\section{Lo Patrimonial Edificado en los Planes de Desarrollo Urbano de Lima}

Hablar de la relación entre planeamiento y patrimonio edificado en Lima exige hacer un ejercicio retrospectivo, no solo a manera de memoria, sino de balance de lo avanzado al respecto, de cara a aportar nuevos componentes estratégicos a ese binomio. Son los antecedentes a la luz de los cuales se puede valorar históricamente lo trabajado y propuesto en el componente de patrimonio edificado en el PLAM 2035. Estos fueron los principales hallazgos durante dicha búsqueda:

\section{Plan del Centro de Lima (1987)}

Con relación al tema de la realidad urbana, se tuvo como política revaluar el patrimonio urbanístico y edilicio. Como programa, se consideraba la revalorización y puesta en valor del patrimonio histórico. Como proyecto, se plantearon nuevas sedes de Comités de Vecinos del Cercado en edificaciones preexistentes.

\section{Plan de Desarrollo Metropolitano de Lima y Callao (1990 - 2010)}

Este plan consistió en la propuesta de una política de patrimonio urbano monumental exclusivamente centrada en el ámbito del Centro Histórico de Lima, a partir de ciertos objetivos:

- Revalorizar el patrimonio urbanístico y edilicio

- Restaurar su traza urbana, alineamientos, altura y apariencia de fachadas

- Restaurar las edificaciones existentes, destinadas a actividades de culto

- Restaurar edificaciones y promover la realización de actividades cívicas, culturales e institucionales, así como de carácter financiero 


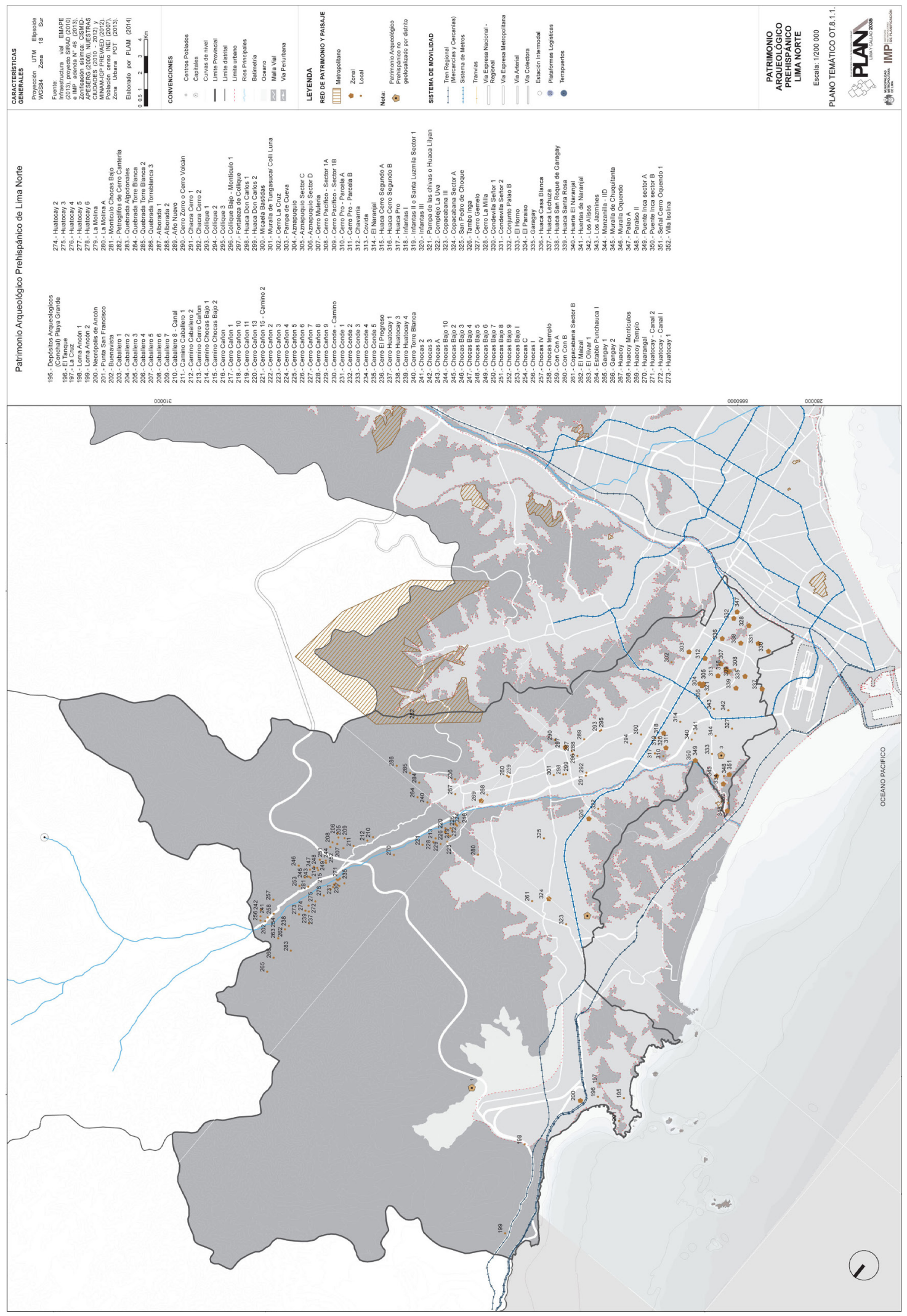

Figura 2. Patrimonio arqueológico prehispánico en Lima Norte.

Fuente: Municipalidad Metropolitana de Lima, 2015. 
- Promover la realización de actividades, y la construcción de establecimientos turísticos y recreativos

- Promover actividades culturales vespertinas y durante los fines de semana, mejorando la seguridad y servicios conexos

Es importante reiterar que en este Plan de Desarrollo Metropolitano no se menciona en absoluto el patrimonio prehispánico y virreinal-republicano en un ámbito externo al Centro Histórico de Lima

\section{Plan Maestro Centro de Lima (1999)}

Este valioso documento urbano destaca por su tratamiento del tema patrimonial. Entre sus principales objetivos destaca el procurar la revitalización de las estructuras espaciales y sociales de valor cultural, y la unidad física del Centro Histórico, para lo cual se propuso impulsar su tratamiento urbanístico de forma compatible con su conservación y rehabilitación. Entre sus principales propuestas destacan las siguientes:

- Identificación de Zonas de Tratamiento (22)

- Corredores de Uso Especializado (9)

- Corredores Turísticos Monumentales (9)

Para lograr este fin de forma más estratégica, se definieron objetivos precisos y específicos para las propuestas referidas.

\section{Plan Maestro del Centro Histórico de Lima al 2025 (2014)}

Las propuestas recogen buena parte del Plan del Centro de Lima (1987) y del Plan Maestro Centro de Lima (1999). Entre sus principales propuestas específicas destacan las siguientes:

- Zonas de tratamiento (19)

- Corredores de Uso Especializado (8)

- CUE Especiales (2)

- Corredores Turísticos Monumentales (7)

\section{Las Apuestas Teóricas de "Lo Edificado como Patrimonio" en el PLAM 2035}

El Diagnóstico Urbano Metropolitano del componente de patrimonio edificado del PLAM 2035 ha desarrollado y compromete otros aspectos críticos de la ciudad, tales como vivienda, gestión de riesgos, vialidad, ambiente, usos de suelo y zonificación, economía, gobernabilidad, entre otros. Esa mirada multidimensional ha permitido utilizar toda la información secundaria accesible e indispensable, la cual fue respaldada con data generada desde diferentes fuentes de información de la ciudad (cartografía + base datos), y ha permitido contribuir a la construcción de una mirada de conjunto de gran valía, especialmente para la definición de políticas públicas metropolitanas de patrimonio, uno de los grandes aspectos del desafío de hacer ciudad y ciudadanía en el Perú, y en Lima.

El objetivo principal consistió en identificar los aspectos estratégicos del estado actual del patrimonio edificado en Lima Metropolitana, como insumos clave para formular políticas públicas metropolitanas de patrimonio que lo pongan en valor social. Esta labor se ha visto enriquecida por un enfoque transversal que no solo ha desarrollado el referido componente de patrimonio edificado como mirada sectorial, sino que ha tenido desarrollos paralelos y complementarios en otras dimensiones del PLAM 2035. 


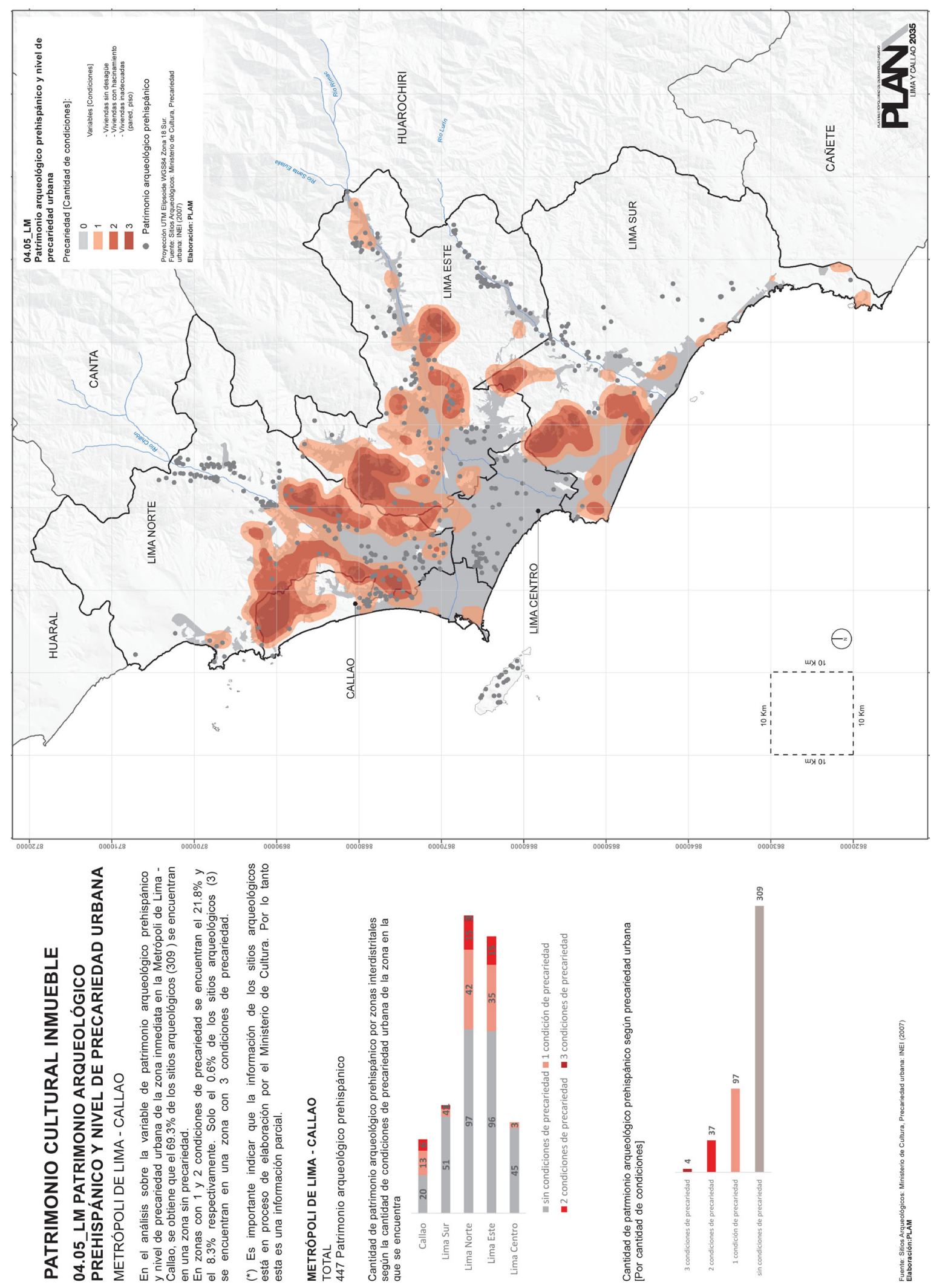

Figura 3. Patrimonio Arqueológico Prehispánico y Precariedad Urbana en Lima Metropolitana.

Fuente: Municipalidad Metropolitana de Lima, 2015. 
Tal es el caso de los siguientes:

- Régimen de Suelo

- Sistemas Urbanísticos

- Áreas Normativas

• Redes Urbanísticas Funcionales

- Programas Urbanísticos y Proyectos Estructurantes

- Instrumentos de Desarrollo del PLAM 2035

-Instrumentos de Gestión

Ejemplos representativos de esta complementariedad y simultaneidad son la aprobación de la Ordenanza Metropolitana de Transferencia de Edificabilidad, el desarrollo de un Área de Tratamiento Normativo de Conservación y Regeneración (ATN1), y el desarrollo de un Proyecto de Recuperación del Complejo arqueológico de la Huaca Mateo Salado, entre los más importantes.

Asimismo, resultó de enorme utilidad el proceso de constituir un marco teórico de reflexión y acción que permitiese un abordaje más cohesionado y estratégico. Para ello, al reconceptuar el patrimonio en el marco de trabajo del PLAM 2035, se tomó como referencia los aportes de los investigadores Josep Ballart Hernández y Jordi Juan-Tresserras, quienes han aproximado una definición que resultó muy pertinente y a la vez esencial para estas labores: "...patrimonio viene del latín; es aquello que proviene de los padres. Según el diccionario, patrimonio son los bienes que poseemos, o los bienes que hemos heredado de nuestros ascendientes. Lógicamente patrimonio es también todo lo que traspasamos en herencia" (Ballart \& Tresserras, 2001, p. 11) Esta definición permite enfatizar que se trata de bienes, es decir, entidades -objetos patrimoniales-, los cuales han recibido la estimación -valor- de parte de algún sujeto natural jurídico o colectivo -sujeto patrimonial-y que son trasmitidos por herencia, por lo que afirman el recuerdo y la transmisión de una herencia compartida.

Al trasladar esta concepción de lo individual a lo colectivo surgen complicaciones a pesar de reconocer su existencia y necesidad comunes, tal como menciona André Desvallées: "Del monumento, soporte de la memoria, hemos pasado al patrimonio, soporte de la identidad" (Prats, 1997, p. 8). En dicho conjunto -como bien indican Pierre Laroche y Cristina Lamandi referenciando a Herb Stovel- la conceptualización del patrimonio ha evolucionado integrando "...all creations and products from both nature and man that constitute the temporal and spatial framework of our lives in time and space" (Mendes, 1999, p. 94), es decir, todas las creaciones y productos generados por la naturaleza o la humanidad que constituyen el marco espacial y temporal de nuestras vidas.

De la misma manera debemos entender que el patrimonio es una construcción social, por lo que resulta "...un artificio, ideado por alguien (o en el decurso de algún proceso colectivo), en algún lugar y momento, para unos determinados fines, e implica, finalmente, que es o puede ser históricamente cambiante, de acuerdo con nuevos criterios o intereses que determinen nuevos fines en nuevas circunstancias" (Prats, 1997, p. 20), por lo cual adquiere un carácter social, participativo y dinámico, como repertorio de significados continuamente interpretados por una comunidad. El patrimonio al ser un concepto relativo, temporal, histórico puede construirse como resultado de la imposición estimativa de un grupo, aunque lo idóneo sería que se originara en el diálogo y en los consensos entre actores sociales, lo que determinaría que la significación del patrimonio resulte de la sumatoria de valores que sobre el mismo tengan los distintos grupos socio-culturales. Así, Fernando Carrión refuerza esta lectura holística de lo patrimonial reconceptualizándolo así: 
- "Es el ámbito de un conflicto social, de la misma manera como ocurre al interior de cualquier núcleo familiar respecto de la herencia. Esto... define los sujetos patrimoniales en sus respectivas tensiones e interrelaciones.

- Es la lógica de la transferencia socio-generacional del valor patrimonial, en la perspectiva del devenir. Esto es, define el carácter de sustentabilidad o la continuidad del cambio". (Carrión (Ed.), 2000, pp. 11-12)

Asimismo, la categoría cultura merece ser definida para una mejor administración de la información a pesar que pueda resultar discutible desde un punto de vista ontológico en virtud a que la polisemia del término cultura es verdaderamente compleja. Sin embargo un experto en la materia como Jorge Cornejo destaca tres acepciones básicas: la primera pertenece a Néstor García Canclini, quien define la cultura como "...la producción de fenómenos que contribuyen, mediante la presentación o reelaboración simbólica de las estructuras materiales, a comprender, reproducir o transformar el sistema social, es decir, todas las prácticas e instituciones dedicadas a la administración, renovación y reestructuración del sentido" (Cornejo, 1987, p. 3).

La segunda definición, planteada por Alessandre N' Daw, se aproxima a la cultura como

"...el conjunto de los modos de expresión, de pensamiento y de acción propios de una comunidad dada. Comprende las creencias, las instituciones, las técnicas que imponen un mismo estilo de vida a los miembros de la sociedad a la que asegura la unidad y la estabilidad aunque sufriendo las transformaciones de esta sociedad, transformaciones a las cuales, por otra parte, ella no cesa de contribuir." (Cornejo, 1987, p. 3)

Por ello, es posible hablar del carácter pluricultural o multicultural de la sociedad peruana.

Finalmente, el tercer sentido que Jorge Cornejo da al término cultura es la "...particular opción de cada ser humano en cuanto a la producción o a la experiencia de lo cultura" (Cornejo, 1987, p. 4), lo cual lo asocia al derecho a la cultura, entendido como el derecho de cada quien a producir libremente sus propias expresiones culturales, y a participar en la vida cultural de la propia comunidad y del mundo.

Por las referencias conceptuales mencionadas, es posible hablar de patrimonio cultural como un conjunto constituido por los bienes culturales -es decir elementos o entidades susceptibles de ser estimados como testimonios de determinada actividad humana por un ente social-, los cuales trascenderán su condición de concreción de la actividad del hombre, para explicitar sus expectativas y miedos, su tecnología, su manera de enfrentar la naturaleza y sentir la belleza, su pensar político y sentir religioso, además del ambiente donde se desarrolló. Justamente estos valores culturales -de naturaleza subjetiva- definirán el nivel de interés general en él y su medio ambiente, la interpretación de su carácter cultural intrínseco y el desarrollo de políticas de tratamiento. Sobre este aspecto, Jukka Jokilehto y Bernard Feilden (1995) destacan entre dichos valores culturales los siguientes:

- Valor identidad (basado en el reconocimiento): ... está relacionado con los lazos emocionales de la sociedad hacia objetos o sitios específicos. Pueden incluir las siguientes características: edad, tradición, continuidad, conmemoración, leyenda; o bien vínculos sentimentales, espirituales o religiosos. Pueden también ser simbólicos, patrióticos o nacionalistas...

- Valor técnico o artístico relativo (basado en la investigación): ....se basa en evaluaciones científicas e histórico-críticas, así como en la determinación de la importancia del diseño del bien cultural, y la relevancia de su concepción y hechura en términos técnicos, estructurales y funcionales... 
- Valor de originalidad (basado en estadísticas): ....se relaciona al bien con otras construcciones del mismo tipo, estilo, constructor, periodo, región, o combinación de estos; definen la originalidad del bien, su representatividad o singularidad... (p. 37)

Sin embargo, estos mismos autores identifican que estos bienes culturales poseen también importantes valores socio-culturales actuales, entendidos como valores de uso correspondientes a la sociedad actual, y a sus circunstancias socioeconómicas y políticas. Indican entre los tipos principales los siguientes:

- Valor económico: ... puede no restringirse a un valor financiero... valor generado por el bien cultural o por la acción de conservación.

- Valor funcional: ....se relaciona con el valor económico, en tanto involucra la continuidad de la clase original de función o la iniciación de un uso compatible...

- Valor educativo: ....incluye su potencial para el turismo cultural, y la concientización sobre la cultura y la historia que promueve como medio para integrar los bienes históricos en el presente.

- Valor social: ... Incluye la interacción social en la comunidad y juega un papel en el establecimiento de la identidad social y cultural.

- Valor político: ...está relacionado con eventos específicos de la historia del bien cultural, asociados a su vez con la región o el país. La relevancia actual del bien puede estar influenciada por esos eventos en tanto coincidan con las intenciones de las prioridades políticas vigentes. (Jokilehto \& Feilden, 1995, pp. 38-39)

Pero, es concluyente el hecho de que, independientemente del ámbito de actuación o apropiación del patrimonio, este es un producto social y, por lo tanto, circunstancia contemporánea de construcción de identidades: "Aujourd'hui, donc, les sociétés modernes choisissent leurs patrimoines. Rien n'est patrimonial par nature ou par un ordre qui nous échapperait; les objets, les éléments immatériels et même les paysages forment un patrimoine quand ils sont proposés à cette fin, par des sujets qui en conviennent et qui s'y reconnaissent" (Le group-Conseil sur la poltique du patrimoine culturel du Québec, 2000, p. 2). Pero, ¿qué implica ver al patrimonio como construcción social? Esencialmente, identificar su aleatoriedad constitutiva permite develar las políticas de la tradición y allanar el camino a la tensión constante por incrementar el patrimonio valorado para que se reconozcan otros grupos sociales.

Al respecto, la Organización de las Naciones Unidas para la Educación, la Ciencia y la Cultura (UNESCO) en la Convención sobre la Protección del Patrimonio Mundial, Cultural y Natural de 1972 consideró en su artículo primero que el conjunto del patrimonio cultural estaba constituido por

- Los monumentos: Obras arquitectónicas, de escultura o de pintura monumentales, elementos o estructuras de carácter arqueológico, inscripciones, cavernas y grupos de elementos, que tengan un valor universal excepcional desde el punto de vista de la historia, del arte o de la ciencia.

- Los conjuntos: Grupos de construcciones, aisladas o reunidas, cuya arquitectura, unidad e integración en el paisaje les dé un valor universal excepcional desde el punto de vista de la historia, del arte o de la ciencia.

- Los lugares: Obras del hombre u obras conjuntas del hombre y la naturaleza así como las zonas, incluidos los lugares arqueológicos, que tengan un valor universal excepcional desde el punto de vista de la historia, del arte o de la ciencia". (PNUD / UNESCO, 1986, p. 86) 
Es muy importante destacar que el Estado peruano ratificó el contenido íntegro de dicha convención el 24 de febrero de 1982, con lo cual ha asumió obligaciones -y reciprocidad con los otros Estados-.

Posteriormente, aquella definición de la Convención sobre la Protección del Patrimonio Mundial, Cultural y Natural de 1972 fue considerada insuficiente, por lo que fue ampliada con la “Declaración de México" (1992), que incluyó además las

...obras de los artistas, arquitectos, músicos, escritores y sabios, así como las creaciones anónimas surgidas del arte popular y el conjunto de valores que dan sentido a la vida. Es decir, obras materiales y no materiales que expresan la creatividad de un pueblo: la lengua, los ritos, las creencias, los lugares y monumentos históricos, la literatura, las obras de arte, los archivos y las bibliotecas. (Tello (Comp.), 2002, pp. 6-7)

En este marco, es posible definir la gestión del patrimonio cultural como el “...conjunto de actuaciones programadas con el objetivo de conseguir una óptima conservación de los bienes patrimoniales y un uso de estos bienes adecuado a las exigencias sociales contemporáneas" (Ballart \& Tresserras, 2001, p. 15). Dicha gestión implica un conjunto de actuaciones destinadas a hacer efectivo el conocimiento, conservación y difusión.

Al plantear el rol de la planificación como actividad de gestión del patrimonio cultural, es necesario recordar que para generar una eficiente interactuación entre la iniciativa pública y la privada es estratégica la creación de un espacio de concertación que incluya a todas las instituciones públicas, privadas y agentes sociales involucrados, que permitiría -merced de su constitución heterogénea- "...discutir libremente... plantear todos los puntos de vista posibles y conocer todos los recursos disponibles, para trazar programas y repartir cargas en un ambiente de absoluta libertad..." (Campillo, 1998, p. 221). Así, la planificación buscará, especialmente, la intercomunicación y coordinación imprescindible entre todos los actores comprometidos, es decir, a la sociedad integral y pertinentemente representada. La planificación de la gestión del patrimonio cultural debe considerar los siguientes aspectos:

- La protección del patrimonio y la identidad local. Hay que evitar la creación de "falsas culturas turísticas" presentando una oferta autóctona que se sustente en la adecuada preservación e integridad de los bienes y valores de la zona. Los beneficios generados [...] deben reinvertirse en la propia mejora del patrimonio.

- La reafirmación del papel de la planificación, ante el peligro del mercado como factor exclusivo de regulación del desarrollo...

- Las personas como protagonistas de su proceso de desarrollo. Los habitantes son el [...] más importante recurso de un territorio [...] es imprescindible implicar el mayor número posible [...] en los proyectos de dinamización del patrimonio...

- La consecución de la mejora de las condiciones de vida de la población local [...] las acciones de preservación deben ir orientadas en primer lugar a la mejora de las condiciones de vida local y, a partir de aquí, poner de manifiesto que la conservación y el uso social del patrimonio son esenciales para la propia supervivencia de la comunidad. (Padrö \& Miró, 2002, p. 66)

Una segunda actividad esencial de gestión del patrimonio cultural es la difusión -o educación informal-, la cual permite al patrimonio cumplir la acción social que le da sentido y asegura con ello que el conocimiento generado con los procesos de investigación retorne a la sociedad que los gesta. Por ende, su finalidad esencial es la orientada a "...desarrollar una actitud ante el patrimonio [...] que permita a la sociedad su identificación, valoración, cuidado y, por supuesto, disfrute" (Querol \& Martínez, 1996, p. 313). No obstante, esta función esencial de las entidades gestoras del patrimonio cultural tiene una influencia aún mayor en la labor de hacer accesibles dichos bienes 
a todo el mundo, ya que "...difundir no es únicamente comunicar la información inherente a un objeto o un lugar, es estimular, hacer reflexionar, provocar y comprometer" (Ballart \& Tresserras, 2001, p. 171).

En ese sentido, destaca la concepción que plantea Marcelo Martín, quien entiende la difusión como una gestión cultural mediadora entre el patrimonio y la sociedad:

Gestión porque implica un proceso complejo que abarca documentar, valorar, interpretar, manipular, producir y divulgar no ya el objeto en sí, sino un modelo comprensible y asimilable de dicho objeto en su relación con su pasado histórico y su medio presente.

Cultural porque se opera con la obra del hombre, tangible, intangible, pasada y presente, que rodea e influye en el ciudadano de hoy hasta ser parte misma de su historia y, por tanto, de su identidad.

Mediadora porque requiere de una técnica y de un soporte material independiente del objeto y ajena al sujeto que la recibe... (Querol \& Martínez, 1996, pp. 313-314)

Otra actividad de gestión del patrimonio cultural es el control, el cual puede definirse como "...el proceso por el cual los responsables de las actividades se aseguran de que éstas se cumplan de acuerdo con el plan trazado, corrigiendo cualquier desviación significativa que se produzca..." (Campillo, 1998, p. 237), es decir, se refiere a la comparación entre lo previsto y lo real. Un buen sistema de control ofrece significativos beneficios, tales como los siguientes:

- Permite la formulación de objetivos explícitos para el conjunto organizacional y para cada una de sus partes.

- Posibilita la comparación de los resultados obtenidos con los objetivos explícitos formulados, configurando la medición y evaluación de la gestión.

- Sirve como elemento importante para la evaluación del trabajo de las personas de la organización.

- Facilita la asignación de incentivos ligados al logro de objetivos.

- Promueve la toma de decisiones correctoras para mejorar el funcionamiento interno y las relaciones de la organización con el entorno.

Justamente, los nuevos y complejos escenarios del patrimonio convocan diversos debates entre los cuales destacan, por su carácter innovador, los referidos al rol que juega, puede o debe jugar el patrimonio en su contexto territorial y social -especialmente las estrategias y las políticas de ordenación y desarrollo territorial- integrando al patrimonio en el desarrollo local. De esta manera, se consolida la visión de una gestión del patrimonio cultural integral e integradora que

....además de restaurar y regular normativamente, significará especialmente la puesta en marcha de un plan de usos y gestión que permita resolver de manera favorable para la sociedad y para el patrimonio el permanente conflicto de la utilización y ocupación del territorio. Es decir, se trata de preguntarse no solo cómo se puede regenerar [...] un bien [...] sino cómo esa regeneración puede convertirse en una de las aspiraciones elementales y principales de sus herederos sociales. (Padrö \& Miró, 2002, p. 60)

\section{Problemas y Desafíos en el Desarrollo del Patrimonio Edificado en el PLAM 2035}

El proceso de elaborar el componente de patrimonio edificado en el plan para Lima Metropolitana (provincias de Lima y Callao) se dividió en cuatro momentos metodológicos: diagnóstico metropolitano, precatálogo, jerarquización y red urbanística de patrimonio, y paisaje. 
En los siguientes textos se explicará cada una de esas fases o momentos, y cuáles fueron los desafíos que involucró el abordaje de cada una de ellas.

\section{Diagnóstico Metropolitano y Precatálogo}

El conjunto del patrimonio edificado de Lima Metropolitana se dividió según períodos históricos, para facilitar el procesamiento de datos y porque existe ya una convención bastante generalizada en la data peruana de asumir el componente cronológico -a partir de estas fechas y períodos- como variable organizadora. Además, esta opción permite seguir la división considerada por el Ministerio de Cultura del Perú.

\section{Patrimonio arqueológico prehispánico}

En el PLAM 2035, se asumió operativamente al patrimonio arqueológico prehispánico como el conjunto de monumentos arqueológicos prehispánicos, considerando que estos son -según la categorización oficial-: "Todos los restos de actividad humana de época Prehispánica que subsisten en el paisaje, de manera superficial, subyacente o subacuática" (Resolución Suprema Nº04-2000-ED. Aprueban Reglamento de Investigaciones Arqueológicas, 2000). (Figura 4)

La construcción del diagnóstico y precatálogo -entendido como compilación estratégica de datos esenciales para la toma de decisiones- se realizó utilizando las tres bases de datos más importantes que se tuvo a disposición. Las dos primeras pertenecen al Ministerio de Cultura. Una de ellas cuenta con 362"puntos" (sin delimitación) del patrimonio arqueológico prehispánico, es decir, con datos de ubicación pero no de forma o superficie protegida. La segunda de ellas, con 266 polígonos, de los cuales 264 eran planos de monumentos arqueológicos prehispánicos declarados patrimonio cultural de la nación y dos de ellos, polígonos propuestos sin declaración oficial, con lo cual se obtenía datos de ubicación, forma o superficie protegida. Dicha información fue brindada directamente al PLAM, en octubre de 2013, luego de diversas y reiteradas solicitudes oficiales, los trámites respectivos y una reunión de coordinación entre equipos de técnicos, funcionarios y asesores de ambas instituciones, desarrollada en la misma sede institucional del Ministerio de Cultura del Perú.

Adicionalmente, se usó la data brindada por la Gerencia de Cultura de la Municipalidad Metropolitana de Lima, con la información y delimitación en polígono de 300 sitios arqueológicos. No son delimitaciones oficiales del Ministerio de Cultura, sino que resultaron producto de una identificación realizada por la Gerencia de Cultura; por ende, resultaba un aporte significativo de georreferenciación que el equipo de dicha gerencia había emprendido.

Esas tres bases de datos se fusionaron y se cotejaron con otros inventarios patrimoniales de referencia:

- Lima Prehispánica (Agurto, 1984)

- Inventario de Monumentos Arqueológicos del Perú. Lima Metropolitana (Primera Aproximación) (Instituto Nacional de Cultura - Municipalidad de Lima Metropolitana, 1985)

- Inventario del Patrimonio Monumental Inmueble - Lima. Valles de Chillón, Rímac y Lurín. Época Prehispánica. Tomos II y III (Facultad de Arquitectura, Urbanismo y Artes - UNI Fundación FORD, 1994)

El objetivo era tener no solo un precatálogo detallado en cifras y datos, sino ubicar los monumentos en el territorio, con lo cual cualquier política e iniciativa de gestión resultaría "territorializada". El desafío de esta fase fue la revisión detallada de cada una de las tres bases de datos referidas y la verificación de cada monumento en los inventarios indicados. El proceso fue largo y detallado, e involucró sentidas idas y vueltas por la heterogeneidad de universos y criterios de las diversas fuentes consultadas. Por 
devenir VOL. 2, N³, ENERO - JUNIO 2015, PP. 113-136 - ESTUDIOS | ISSN 2312-7570

UnIVERSIDAD NACIONAL DE INGENIERIA, LIMA
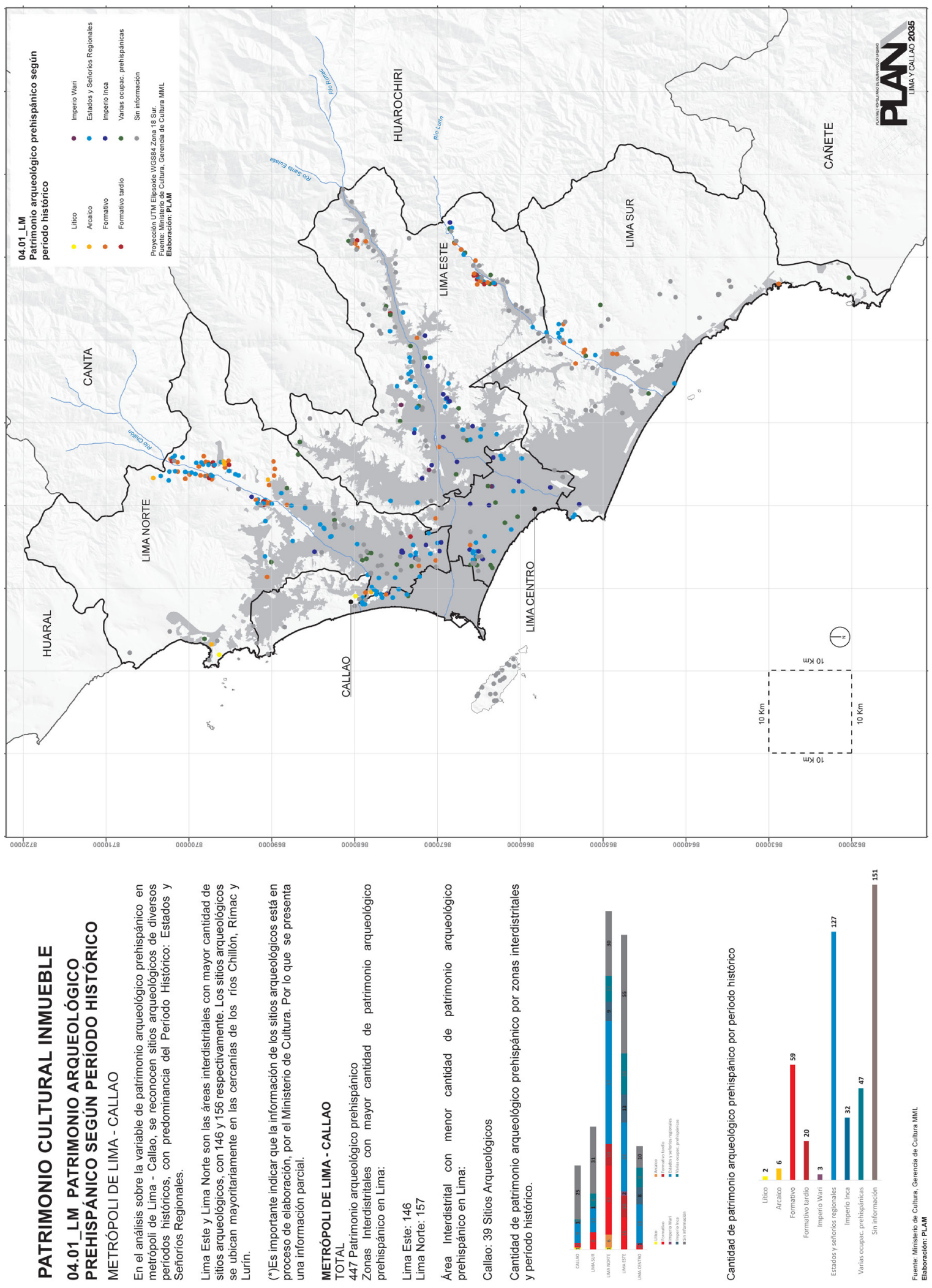

Figura 4. Patrimonio arqueológico prehispánico en Lima Metropolitana según período histórico.

Fuente: Municipalidad Metropolitana de Lima, 2015. 
ejemplo, en algunos casos, la ubicación de un mismo monumento no coincidía en las tres bases de datos. Se verificó monumento por monumento, y se cruzó la información de las instituciones mencionados con inventarios previos y detallados.

La posibilidad de contrastar el nivel de afectación de los sitios arqueológicos en Lima Metropolitana y la zonificación distrital propuesta para dichos territorios ha permitido identificar importantes hallazgos en este esfuerzo inédito. Para ello, se seleccionaron 32 sitios de complejidades y entornos urbanos disímiles, provenientes de los diversos ámbitos territoriales de Lima: Lima Centro, Lima Norte, Lima Este, Lima Sur y Callao. Se identificó en general un mayor nivel de afectación en zonas periurbanas que en la Lima más consolidada urbanísticamente hablando, porque en esta última ya tuvo lugar la depredación y degradación durante el asentamiento de sus urbanizaciones más antiguas. Adquiere esa lógica evidenciada en estas cifras y territorialización (Figuras 5 y 6 ).

\section{Patrimonio histórico colonial y republicano}

En el marco del PLAM 2035, el patrimonio histórico colonial y republicano fue concebido como el conjunto de monumentos provenientes de esa época, considerando que estos se encuentran definidos oficialmente como

Todos los restos de actividad humana de época colonial y republicana que subsisten en el paisaje, de manera superficial, subyacente o subacuática. Se consideran así a las obras arquitectónicas, escultóricas y pictóricas monumentales y las inscripciones correspondientes a estas épocas. Los trabajos de arqueología en este caso, servirán para el estudio de los elementos materiales constitutivos de estos monumentos. (Resolución Suprema № 004-2000-ED. Aprueban Reglamento de Investigaciones Arqueológicas, 2000)

En el caso del patrimonio histórico colonial y republicano, se utilizó el listado oficial brindado por el Ministerio de Cultura, donde se consideran 1650 bienes integrantes del patrimonio cultural de la nación para el caso de Lima Metropolitana (provincias de Lima y Callao). Además, esta opción permite seguir la división y denominación considerada por el Ministerio de Cultura del Perú. La información consistía en una base de datos sin ninguna cartografía, solo con referencia nominal al distrito, provincia o departamento de localización.

La mayoría de los 1650 monumentos históricos indicados se ubican en los distritos que tienen zonas monumentales, como Cercado de Lima -que no es un distrito pero para efectos de este universo se le consideró así-, Rímac, Barranco, Cercado de El Callao y Pueblo Libre. Por este motivo, se optó por completar la ubicación priorizando los monumentos que se encuentran fuera de las zonas monumentales establecidas, porque muy probablemente los otros se hallaban ya incluidos en dichas zonas.

El desafío de esta fase fue la revisión exhaustiva de la información, la construcción de una única base de datos que integre lo avanzado fragmentariamente y la realización de una cartografía general, georreferenciando el mayor porcentaje posible de monumentos. De igual manera, el trabajo fue detallado, para lograr ubicar con precisión los monumentos mencionados. Hablamos de un aporte significativo con información que permita ser gestionada estratégicamente desde el territorio.

\section{Bienes contemporáneos con valor monumental}

Otro aporte significativo que asumió el PLAM 2035 fue la consideración de los Ilamados bienes contemporáneos con valor monumental, los cuales fueron concebidos como el conjunto de edificaciones o ambientes urbanos del siglo XX en adelante que, sin haber sido declarados patrimonio cultural de la nación, cuentan con características arquitectónicas o urbanas destacadas, por lo que deberían incluirse dentro de los conjuntos patrimoniales, y la Red de Patrimonio y Paisaje. Esto no implica incluirlas inme- 
devenir Vol. 2, N³, ENERO - JUNIO 2015, PP. 113-136 - EstudIOS | ISSN 2312-7570

UnIVERSIDAD NACIONAL DE INGENIERÍA, LIMA
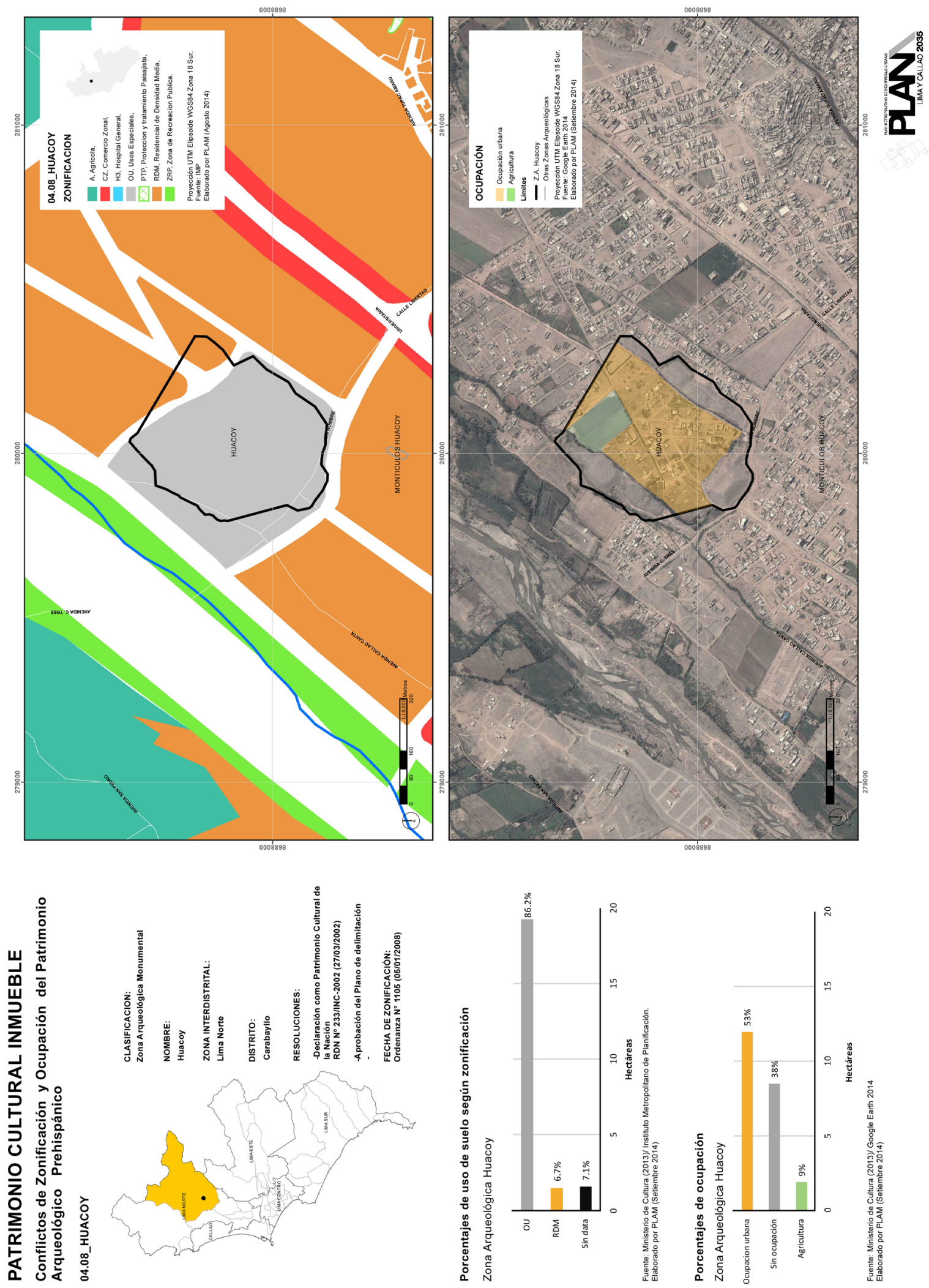

Figura 5. Conflictos de Zonificación y Ocupación del Patrimonio arqueológico prehispánico-Huacoy (Lima Norte). Fuente: Municipalidad Metropolitana de Lima, 2015. 

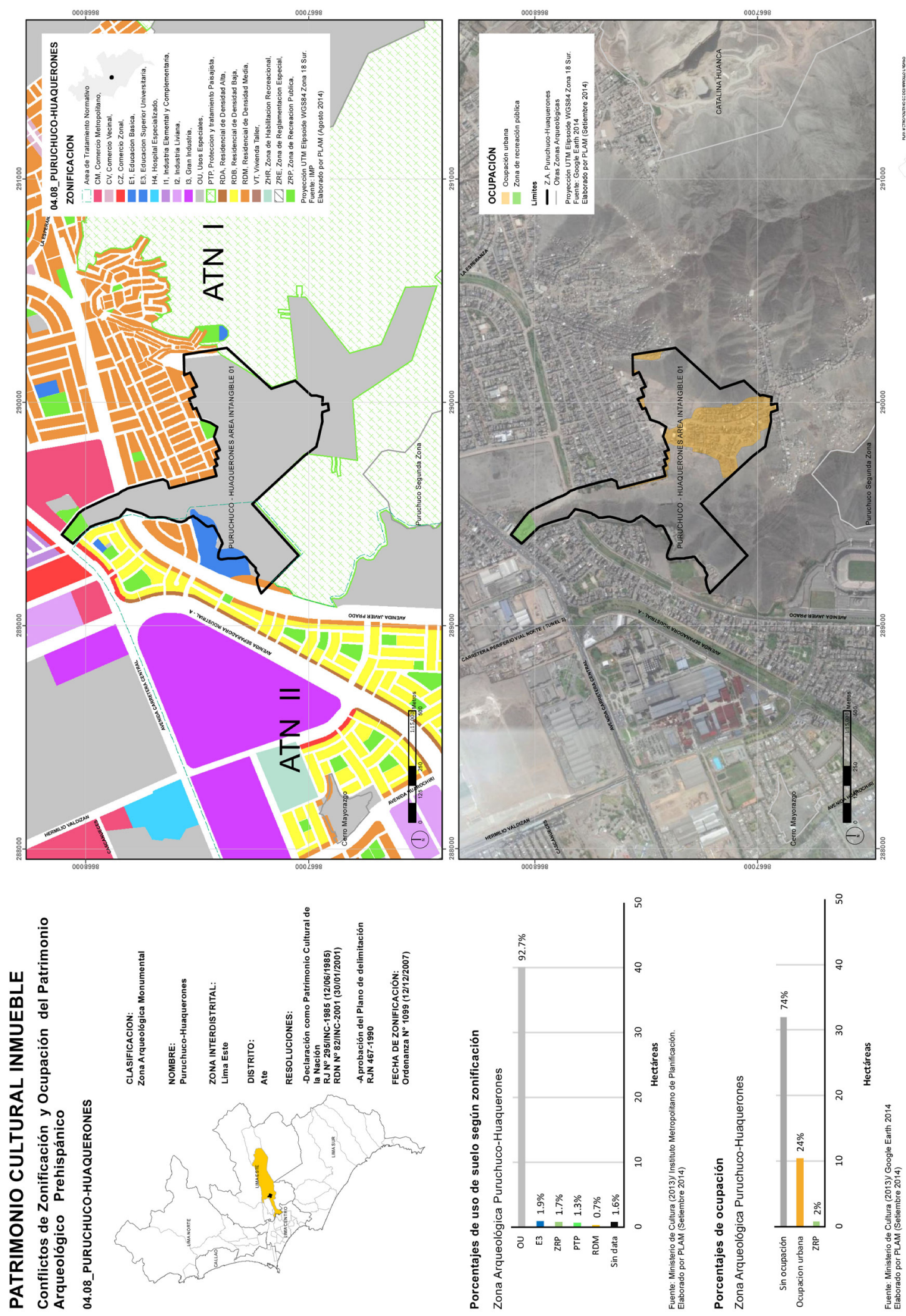

Figura 6. Conflictos de Zonificación y Ocupación del Patrimonio arqueológico prehispánico- Puruchuco-Huaquerones (Lima Este). Fuente: Municipalidad Metropolitana de Lima, 2015. 
diatamente en el conjunto de bienes integrantes del Patrimonio Cultural de la Nación -ya que ello solo podrá ser determinado posteriormente por el Ministerio de Cultura-, sino otorgarles el reconocimiento público, de parte de la administración local, por sus méritos y valores.

El precatálogo de los bienes contemporáneos con valor patrimonial se realizó empleando tres bases de datos:

- Patrimonio del Siglo XX (Colegio de Arquitectos del Perú. Comisión Nacional de Defensa del Patrimonio Arquitectónico, Urbanístico, Histórico y Natural del CAP, 2014)

- Edificios Emblemáticos del Movimiento Moderno en el Perú (DOCOMOMO Documentation and Conservation of buildings, sites and neighbourhoods of the Modern Movement, 2014).

- Inventario del Patrimonio Monumental Inmueble - Lima. Valles de Chillón, Rímac y Lurín. Época Contemporánea. Tomos IV. (Facultad de Arquitectura, Urbanismo y Artes - UNI Fundación FORD, 1994).

Para la estructuración final de estos bienes en el precatálogo, las tres bases de datos se fusionaron. Se eliminaron aquellas edificaciones incluidas actualmente como bienes integrantes del patrimonio cultural de la nación y, asimismo, se eliminaron aquellas edificaciones desaparecidas al año 2014.

El desafío de este momento metodológico fue revisar cada bien contemporáneo. Una vez ubicados en el territorio, se debía verificar su existencia, pues muchos bienes habían sido demolidos en los años previos debido al acelerado proceso de densificación y especulación inmobiliaria experimentado en algunos distritos de las zonas centrales de Lima Metropolitana (Figura 7).

\section{Jerarquización}

Se consideraron tres variables para diferenciar los bienes integrantes del patrimonio cultural de la nación en función de su potencialidad urbana -lo cual denominamos jerarquización -: valoración científica, nivel de prioridad turística y superficie aproximada.

Esto se realizó para el patrimonio arqueológico prehispánico, y el patrimonio histórico colonial y republicano.

\section{Patrimonio arqueológico prehispánico}

a) Variable: Valoración científica

Para aplicar esta variable, se recurrió a la información de los inventarios:

- Informe sobre los Monumentos Arqueológicos de Lima (Junta Deliberante Metropolitana de Monumentos Históricos, Artísticos y Lugares Arqueológicos de Lima, 19621963).

- Lima Prehispánica (Agurto, 1984).

- Inventario de Monumentos Arqueológicos del Perú. Lima Metropolitana (Primera Aproximación), (Instituto Nacional de Cultura - Municipalidad de Lima Metropolitana, 1985).

- Inventario del Patrimonio Monumental Inmueble - Lima. Valles de Chillón, Rímac y Lurín. Época Prehispánica. Tomos II y III (Facultad de Arquitectura, Urbanismo y Artes - UNI Fundación FORD, 1994). 

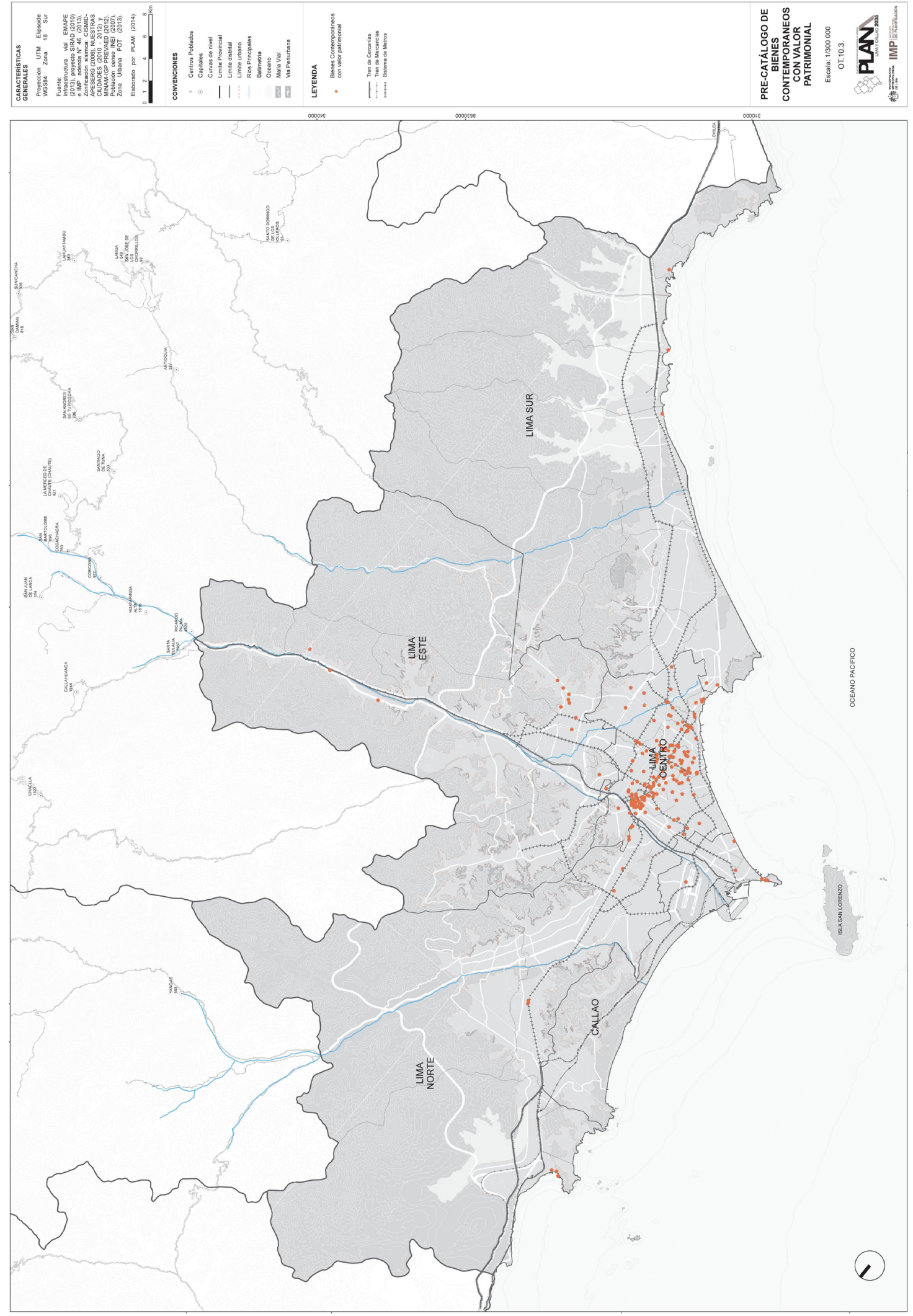

Figura 7. Precatálogo de Bienes Contemporáneos con Valor Monumental.

Fuente: Municipalidad Metropolitana de Lima, 2015. 
La información contenida en cada uno de estos inventarios se subdividió y se le asignó una valoración numérica. Este método ayudó a cuantificar y luego recategorizar la información. El principal desafío en esta etapa fue el procesamiento de información, debido al volumen de esta en cada inventario analizado. Se cotejó la información monumento por monumento, en un esfuerzo por obtener una valoración lo más completa posible.

b) Variable: Prioridad turística

Esta variable se desarrolló sobre la base de la información brindada por la Gerencia de Turismo de la Municipalidad Metropolitana de Lima, no solo a solicitud de parte, sino con orientaciones en función de los componentes que era necesario evaluar. Dicha data resultó en la lista de recursos turísticos considerados por el Ministerio de Turismo (MIN(CETUR) y, en algunos pocos casos, en la jerarquización que reciben dichos recursos.

La principal limitación de esta etapa fue la escasa información sobre monumentos arqueológicos prehispánicos disponible en el Ministerio de Turismo. La gran mayoría no aparece como recurso turístico, y solo una fracción tiene una jerarquización dentro de la institución mencionada.

c) Variable: Superficie aproximada

Para analizar esta variable se consideraron los monumentos arqueológicos que poseen delimitación del Ministerio de Cultura o, en su defecto, delimitación de la Gerencia de Cultura de la MML.

El principal desafío en esta fase fue la ausencia de información detallada sobre algunos monumentos arqueológicos prehispánicos. No todos los monumentos arqueológicos prehispánicos poseen delimitación oficial, ni asumida.

Finalmente, al cruzarse las tres variables, se pudo establecer una jerarquización de los monumentos arqueológicos prehispánicos, de la cual resultaron tres niveles de potencialidad urbana: metropolitano, zonal y local.

\section{Patrimonio histórico colonial y republicano}

a) Variable: Valoración científica

La variable de valoración científica se desarrolló en función de la clasificación de la Junta Deliberante Metropolitana de Lima (1962), en la que existían ya cuatro valoraciones. A cada una de las clasificaciones se le otorgó una valoración numérica.

De un modo similar a otras fases, el desafío fue sistematizar la información del libro referida a cada monumento histórico y, posteriormente, darle una valoración a dicha información. El proceso de revisión de la información se realizó de manera detallada.

b) Variable: Prioridad turística

Esta variable se desarrolló de acuerdo con la información brindada por la Gerencia de Turismo de la Municipalidad Metropolitana de Lima, no solo a solicitud de parte, sino orientada en función de los componentes que era necesario evaluar.

De dicha data resultó la lista de recursos turísticos considerados por el Ministerio de Turismo (MINCETUR) y la jerarquización de dichos recursos realizada por la Gerencia de Turismo de la MML.

La principal limitación de esta etapa fue la escasa información de monumentos históricos coloniales y republicanos en el Ministerio de Turismo. La gran mayoría no aparece como recurso turístico; solo aparecen los monumentos más importantes y reconocidos.

El procesamiento de la información se realizó detaladamente. Se debe precisar que en este caso también la cantidad de monumentos con información referida a esta variable era menor en comparación a otras fases. 
c) Variable: Superficie aproximada

Para analizar esta variable, la información respecto al tamaño se consideró solo para las zonas monumentales.

La principal limitación de esta fase fue la escasa información referida al tema, sobre la gran mayoría de monumentos. En la base de datos del ministerio no se incluía dicha información.

Finalmente, al cruzarse las tres variables, también se pudo jerarquizar los monumentos arqueológicos coloniales y republicanos en tres niveles: metropolitano, zonal y local.

\section{Red de Patrimonio y Paisaje}

Luego de cuantificar, cartografiar y jerarquizar el patrimonio existente, se procedió a realizar una propuesta, definiendo una orientación al trabajo articulado mediante el formato de una Red de Patrimonio y Paisaje.

Se propusieron conjuntos culturales, considerados como las concentraciones de bienes patrimoniales (patrimonio arqueológico prehispánico, e histórico colonial y republicano) y de los bienes contemporáneos con valor patrimonial agrupados según las dinámicas de su entorno, como el nivel de consolidación urbano y la presencia de la estructura ecológica.

Se identificaron primero las concentraciones de bienes patrimoniales y con valor patrimonial, y luego dichas concentraciones se dividieron en tres grupos: conjunto cultural central, conjunto cultural periférico (ubicado en las áreas interdistritales de Lima Norte, Lima Sur, Lima Este y la Provincia Constitucional del Callao) y corredor cultural.

El principal reto y desafío de esta etapa final fue intersectar el tema de patrimonio edificado con otras áreas de análisis, como áreas libres, usos de suelo, movilidad urbana, equipamiento urbano, centralidades, etc.

Se trabajaron las propuestas de la Red de Patrimonio desde de un enfoque multidisciplinar, de manera que dichas propuestas sean lógicas, sostenibles y se interrelacionen con el resto de la ciudad.

\section{Lo Edificado como Patrimonio en Lima Metropolitana desde el PLAM 2035}

Finalmente, es importante detallar a continuación el resultado del procesamiento de información, superando los desafíos previamente indicados.

\section{Diagnóstico Metropolitano y Precatálogo}

\section{Patrimonio arqueológico prehispánico}

Se debe indicar que se fusionó y complementó la información del Ministerio de Cultura y de la Gerencia de Cultura MML. De esta manera, se obtuvo un universo de 447 monumentos arqueológicos prehispánicos geolocalizados (es decir, ubicados en el territorio) y 107 no geolocalizados (declarados monumentos por decreto, pero sin indicación de coordenadas, solo distrito).

\section{Patrimonio histórico colonial y republicano}

Se tomó el listado oficial del Ministerio de Cultura, que comprende 1650 bienes integrantes del patrimonio de dicho período. Se logró geolocalizar el 10\% aproximadamente.

\section{Bienes contemporáneos con valor monumental}

Se fusionaron tres listados de instituciones para obtener la lista de bienes contemporáneos con valor monumental. No se trata de monumentos declarados, sino de edificaciones o barrios con características y valores particulares. Se obtuvo un universo de 211 bienes contemporáneos con valor monumental geolocalizados y 10 no geolocalizados. 


\section{Jerarquización}

\section{Patrimonio arqueológico prehispánico}

Para la jerarquización del patrimonio arqueológico prehispánico se consideró aquel que se encuentra geolocalizado (447). El patrimonio arqueológico no geolocalizado (107 monumentos) no entró en esta jerarquización al no contar con una ubicación determinada e información sobre los monumentos. Se determinó que existen 15 monumentos arqueológicos prehispánicos de jerarquía metropolitana, 106 monumentos de jerarquía zonal y 326 monumentos de jerarquía local.

\section{Patrimonio histórico colonial y republicano}

Para la jerarquización del patrimonio histórico colonial y republicano se ha considerado la totalidad de los monumentos de dicho período. Sin embargo, solo un $10 \%$ del total ha sido geolocalizado y aparece en los planos. Se determinó que existen 216 monumentos históricos coloniales y republicanos de jerarquía metropolitana, 58 monumentos de jerarquía zonal y 1376 monumentos de jerarquía local.

\section{Red de Patrimonio y Paisaje}

La Red de Patrimonio y Paisaje considera tres tipos de conjunto patrimonial: conjunto cultural central (cuatro en Lima Metropolitana), conjunto cultural periférico (10 en Lima Metropolitana) y corredor cultural (CC. Chillón, CC. Rímac y CC. Lurín)

\section{Lecciones Aprendidas}

A manera de conclusiones validadas a partir de la sistematización de esta experiencia es posible identificar las siguientes:

\section{Sobre la Gestión Patrimonial}

- La concertación de intereses permite ir hacia una creciente colaboración y corresponsabilización en la gestión de los proyectos patrimoniales, promoviendo experiencias más descentralizadas propatrimonales, dotando a los proyectos patrimoniales de vinculación al territorio donde están circunscritos, y favoreciendo la confluencia en la gestión y la toma de decisiones conjunta entre los representantes políticos, los profesionales y la sociedad civil.

- La clave de la puesta en valor patrimonial es apostar por principios de participación y autonomía, así como por la diversificación de las formas de financiación.

- El turismo cultural representa una clave muy importante para la dinámica urbano-monumental, aunque pasa por la capacidad de brindar respuestas adecuadas, específicas e imaginativas a las nuevas demandas de los usuarios -ciudadanos y visitantes-, cada vez más motivados por descubrir territorios y culturas. Se trata de convertir al patrimonio edificado en un producto turístico, pero siempre basado en su correcta conservación y aprovechamiento.

- Los sistemas de presentación del patrimonio invocan que en la mediación del patrimonio con el público se generalicen las técnicas de interpretación, que manifiesten los cambios y retos actuales en la comunicación con el público.

\section{Sobre el proceso de diagnóstico/propuesta patrimonial}

- La transversalidad exige el reconocimiento de la capacidad que puede tener el patrimonio cultural de actuar en políticas transversales o transectoriales, que evidencien la interrelación existente entre el patrimonio y otros ámbitos competenciales. Ello exigió elaborar un diagnóstico y propuesta que recogiera la multidimensionalidad del objeto patrimonial con relación a las otras dimensiones de la dinámica urbana. 
- La aplicación del principio de subsidiariedad conlleva a desarrollar políticas, planes y programas más cercanos al ciudadano, no solo como proximidad, sino como corresponsabilización. En la experiencia del PLAM 2035, ello fue fundamental para lograr una sostenibilidad basada en el ciudadano, y sus asociaciones e instituciones.

- La planificación reconoce la necesidad de trabajar siempre a partir de una mirada de carácter estratégico, pensando siempre en la consecución de los objetivos y definiendo escenarios, actores y roles. Por ello, la jerarquización de bienes patrimoniales, y la definición de territorios y de aliados resultaron esenciales para tentar impactos más eficaces y coherentes con las especificidades de la realidad metropolitana limeña

- Los proyectos de desarrollo local demandan que cualquier estrategia de promoción local y regional se sustente en proyectos de desarrollo turístico del patrimonio cultural y natural, los cuales deben tener como objetivo esencial el conseguir la doble efectividad de preservar las culturas y desencadenar dinámicas de desarrollo urbano en las comunidades que le dan sentido al patrimonio. El componente de patrimonio edificado del PLAM 2035 se entendía asimismo no solo desde lo cultural, sino como detonador de una mejor experiencia de vida urbana.

Sin estas apuestas, muy probablemente, la batalla seguirá estando perdida...

\section{Referencias}

Agurto, S. (1984). Lima prehispánica. Lima, Perú: Municipalidad de Lima Metropolitana.

Agurto, S. (1992). Situación del Patrimonio Monumental. Huaca, (3), 4-8.

Ballart, J. \& Tresserras, J. (2001). Gestión del patrimonio cultural. Barcelona, España: Ariel.

Campillo, R. (1998). La gestión y el gestor del patrimonio cultural. Murcia, España: KR.

Carrión, F. (Ed.). (2000). Desarrollo cultural y gestión en centros históricos. Quito, Ecuador: Facultad Latinoamericana de Ciencias Sociales (FLACSO) - Ecuador.

Comisión Nacional de Defensa del Patrimonio Arquitectónico, Urbanístico, Histórico y Natural del Colegio de Arquitectos del Perú. (2014). Patrimonio del Siglo XX . Lima, Perú: CAP.

Cornejo, J. (1987). Cuadernos de Historia III: Estado y cultura en el Perú republicano. Lima, Perú: Departamento Académico de Ciencias Humanas de la Universidad de Lima.

Documentation and Conservation of Buildings, Sites and Neighbourhoods of the Modern Movement. (2 de julio de 2014). Recuperado de http://docomomoperu.com/emblematicos.php

Facultad de Arquitectura, Urbanismo y Artes de la UNI \& Fundación Ford. (1994). Inventario del Patrimonio Monumental Inmueble - Lima. Valles de Chillón, Rímac y Lurín. Lima, Perú.

Instituto Nacional de Cultura y Municipalidad de Lima Metropolitana. (1985). Inventario de Monumentos Arqueológicos del Perú. Lima Metropolitana (Primera Aproximación). Lima, Perú.

Jokilehto, J. \& Feilden, B. (1995). Manual para el manejo de los sitios del Patrimonio Mundial Cultural. Bogotá, Colombia: Instituto Colombiano de Cultura.

Le group-Conseil sur la poltique du patrimoine culturel du Québec. (2000). Notre patrimoine, un présent du passé. Québec, Canadá: Gouvernement du Québec.

Mendes, S. (Org.). (1999). Conservation and urban sustainable development: A theoretical framework. Recife, Brasil: Centro de Conservacao Integrada Urbana e Territorial (CECI) - Universidade Federal de Pernambuco.

Municipalidad Metropolitana de Lima. (2 de julio de 2015). Plan Metropolitano de Desarrollo Urbano de Lima. Recuperado de http://goo.gl/xuBywc

Padrö, J. \& Miró, M. (2002). Retos del patrimonio en el siglo XXI, gestión creativa y desarrollo territorial. Periférica Volumen(Número), pp-pp.

Programa de las Naciones Unidas para el Desarrollo \& Programa de las Naciones Unidas para la Educación, la Ciencia y la Cultura. (1986). Convenciones y recomendaciones de la UNESCO sobre la protección del patrimonio cultural. Lima, Perú: Autor. 
devenir Vol. 2, N³, ENERO - JUNIO 2015, PP. 113-136 - EstudIOS | ISSN 2312-7570

UNIVERSIDAD NACIONAL DE INGENIERÍA, LIMA

Prats, L. (1997). Antropología y patrimonio. Barcelona, España: Ariel.

Querol, M. Á. \& Martínez, B. (1996). La gestión del patrimonio arqueológico en España. Barcelona, España: Alianza Universal Textos.

Resolución Suprema N 004-2000-ED. Aprueban Reglamento de Investigaciones Arqueológicas. (24 de enero de 2000). Lima, Perú.

Rincón, F. (Ed.). (2000). Memorias Cátedra UNESCO. Gestión integral del patrimonio en centros históricos. Manizales, Colombia: UNESCO.

Riobóo, F. (2002). Una forma de entender la problemática patrimonial. Córdoba, España: Programa de Patrimonio Histórico de la Diputación de Córdoba.

Tello, S. (Comp.). (2002). En torno al Patrimonio e Interdisciplinariedad. Lima, Perú: Escuela Profesional de Turismo y Hotelería de la Universidad de San Martín de Porres. 